\title{
An Experimental Study on Wave Absorber Performance of Combined Punching Plate in a Two-Dimensional Mini Wave Tank
}

\author{
Hyen-Cheol Jung ${ }^{(1)}$ and Weoncheol Koo ${ }^{\left({ }^{2}\right.}$ \\ ${ }^{1}$ Researcher, Department of Naval Architecture and Ocean Engineering, Inha University, Incheon, Korea \\ ${ }^{2}$ Professor, Department of Naval Architecture and Ocean Engineering, Inha University, Incheon, Korea
}

KEY WORDS: Wave absorber, Punching plate, Reflected wave, 2D mini wave tank, Reflection coefficient

\begin{abstract}
In order to perform a precise wave tank experiment, it is necessary to maintain the incident wave generated by the wavemaker in a steady state and to effectively remove the reflected waves. In this paper, a combined sloping-wall-type punching plate wave absorber was proposed to attenuate reflected waves effectively in a two-dimensional mini wave tank. Using the four-point reflection separation method, the reflected waves were measured to determine the reflection coefficients. Experiments were conducted under various punching plate porosities, sloping plate angles, and incident wave conditions to evaluate the performance of the combined punching plate wave absorber. The most effective wave absorbing performance was achieved when the porosity was $10 \%$ and the inclination angle of the punching plate was $18.6^{\circ}$ under the present condition. It was also found that the installation of the sloping plate could improve the wave attenuation performance by generating the shoaling effect of the incident wave.
\end{abstract}

\section{Introduction}

A two-dimensional (2D) wave tank generates water waves and has been used as an experimental device to perform various hydrodynamic analyses; for example, it is used to investigate the wave-wave and wave-body interactions. However, such a wave tank generates unnecessary reflected waves at the end wall of the tank owing to its limited physical size. Therefore, it is crucial to install an efficient wave absorber to continuously measure the waves generated by the wave maker and maximize the observation range.

Jung and Cho (1999) confirmed that when used as a wave absorber, a flat punching plate performs better than conventional wave absorbers. Cho and Hong (2004) confirmed that the porosity of the punching plate should be $10 \%$ and its sloping angle should be within $10^{\circ}-20^{\circ}$ to achieve maximum wave absorption performance when an inclined punching plate is used as a wave absorber.

In this paper, we proposed a combined wave absorber by combining a flat punching plate and a sloping punching plate to minimize the reflected waves in a 2D mini wave tank. Additionally, an experimental study was conducted to evaluate the performance of the proposed punching plate. We separated the incident waves and the reflected waves using the least square method (Mansard and Funke, 1980) to determine the performance of the wave absorber. This method is to minimize the sum of squares of error between the waveform obtained through an equation and the measured waveform. This method usually uses three wave gauges to measure wave elevations. However, in this study, we measured the incident waves and the separated reflected waves by installing four wave gauges for better accuracy.

The sections of the measured waves to be analyzed should be selected appropriately to achieve an accurate separation between the incident waves and reflected waves. The reflected waves were measured in the steady-state section until the incident waves were reflected from the wave absorber at the end of the tank and then reflected again from the wave maker and reached the same wave gauge. The measured waves were separated into incident waves and reflected waves. In this study, we proposed a novel combined punching plate wave absorber that combined a flat punching plate and sloping punching plate. Additionally, we determined the wave absorption performance, and porosity and slope conditions required for the optimal wave absorption performance of the proposed punching plate.

Received 14 February 2021, revised 8 March 2021, accepted 12 March 2021

Corresponding author Weoncheol Koo: +82-32-860-7348, wckoo@inha.ac.kr

(C) 2021, The Korean Society of Ocean Engineers

This is an open access article distributed under the terms of the creative commons attribution non-commercial license (http://creativecommons.org/licenses/by-nc/4.0) which permits unrestricted non-commercial use, distribution, and reproduction in any medium, provided the original work is properly cited 


\section{Separation of Reflected Waves}

In this study, we installed four wave gauges at appropriate intervals in the wave tank to separate the incident and reflected waves. We used the reflected wave separation method proposed by Goda and Suzuki (1977) using the measured wave height data, referring to Suh et al. (2001) and Park et al. (1992). When the frequency of the incident wave is $\omega$, the incident wave elevation $\left(\zeta_{I}\right)$ and the reflected wave elevation $\left(\zeta_{R}\right)$ can be expressed using Eqs. (1) and (2), respectively.

$$
\begin{gathered}
\zeta_{I}=\frac{H_{I}}{2} \cos \left(k x-w t+\varepsilon_{I}\right) \\
\zeta_{R}=\frac{H_{R}}{2} \cos \left(k x+w t+\varepsilon_{R}\right)
\end{gathered}
$$

Here, $H_{I}$ and $H_{R}$ denote the incident wave height and reflected wave height, respectively, $\epsilon_{I}$ and $\epsilon_{R}$ denote the phase difference of the incident wave and reflected wave, respectively, and $k$ denotes the wave number. The time series of waves measured at a particular position by the superposition method of the incident and reflected waves can be represented by Eq. (3):

$$
\zeta_{n}(t)=\frac{H_{I}}{2} \cos \left(k l_{n}-w t+\varepsilon_{I}\right)+\frac{H_{R}}{2} \cos \left(k l_{n}+w t+\varepsilon_{R}\right)+e_{n}(t)
$$

where $e_{n}(t)$ refers to the measurement error for the non-linear interference or noise of waves included in the wave height data measured by the $n^{\text {th }}$ measurement position ( $n^{\text {th }}$ wave gauge), and $l_{n}$ indicates the distance from the reference point to the $n^{\text {th }}$ measurement position.

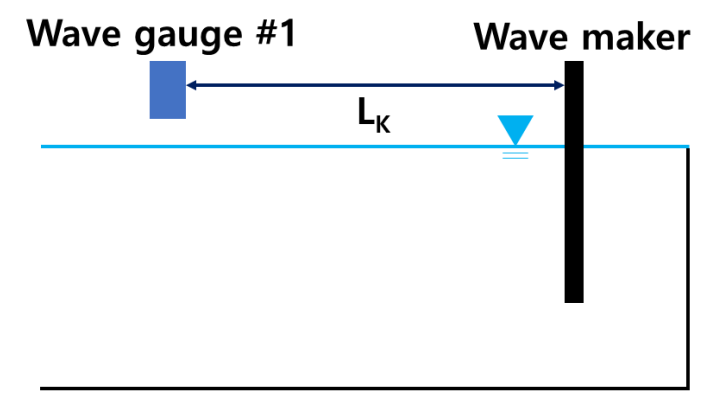

Fig. 1 Distance between the wave maker and the first wave gauge

The reference point was set at a distance of $2 \mathrm{~m}\left(L_{k}\right)$ from the wave maker to the first wave gauge (Fig. 1). If Eq. (3) was organized using a trigonometric theorem, it can be represented as Eq. (4), and the equation for $X$ is provided in the appendix.

$$
\begin{array}{r}
\zeta_{n}(t)=X_{1} \cos \left(w t-k l_{n}\right)+X_{2} \cos \left(w t+k l_{n}\right) \\
+X_{3} \sin \left(w t-k l_{n}\right)-X_{4} \sin \left(w t+k l_{n}\right)+e_{n}(t)
\end{array}
$$

Meanwhile, the measurement data error for separating the incident and reflected waves can be expressed as the sum of the squares of errors included in the measurement data, as shown in Eq. (5).

$$
\begin{aligned}
& E=\sum_{n=1}^{N} \int_{0}^{T_{m}}\left(e_{n}(t)\right)^{2} d t \\
& \frac{\partial E}{\partial X_{j}}=0
\end{aligned}
$$

Here, $N$ represents the number of wave gauges, and $T_{m}$ represents the measured time. With error $(E)$, which is the sum of measurement errors, if the differential value for $X_{i}$, a coefficient related to the wave heights and phases of incident and reflected waves, becomes 0 , the error for each coefficient can be minimized. If four $X_{1}-X_{4}$ were calculated using this method, the height and phase of the incident and reflected waves can be obtained. Eq. (7), which is a linear algebraic matrix equation, can be composed using Eq. (6), which can minimize the minimum/maximum of the error $(E)$ :

$$
\left(\begin{array}{llll}
c_{11} & c_{12} & c_{13} & c_{14} \\
c_{21} & c_{22} & c_{23} & c_{24} \\
c_{31} & c_{32} & c_{33} & c_{34} \\
c_{41} & c_{42} & c_{43} & c_{44}
\end{array}\right)\left(\begin{array}{l}
X_{1} \\
X_{2} \\
X_{3} \\
X_{4}
\end{array}\right)=\left(\begin{array}{l}
F_{1} \\
F_{2} \\
F_{3} \\
F_{4}
\end{array}\right)
$$

where $C_{i j}$ expresses the right side of Eq. (4) as a trigonometric function, and $F_{j}$ denotes the wave measured at each wave gauge. This equation is provided in detail in the appendix. By calculating Eq. (7), the coefficient $X_{i}$ can be obtained. Finally, Eqs. (8)-(11) were applied to calculate the wave height and phase of the incident and reflected waves.

$$
\begin{aligned}
& \varepsilon_{I}=\tan ^{-1} \frac{X_{3}}{X_{1}} \\
& \varepsilon_{R}=\tan ^{-1} \frac{X_{4}}{X_{2}} \\
& H_{I}=\frac{2 X_{1}}{\cos \left(\varepsilon_{I}\right)} \text { or } \frac{2 X_{3}}{\sin \left(\varepsilon_{I}\right)} \\
& H_{R}=\frac{2 X_{2}}{\cos \left(\varepsilon_{R}\right)} \text { or } \frac{2 X_{4}}{\cos \left(\varepsilon_{R}\right)}
\end{aligned}
$$

\section{Experimental Equipment and Description}

\subsection{Two-dimensional Wave Tank}

In this experimental study, we used the 2D mini wave tank in Inha University. The wave tank was $0.3 \mathrm{~m}$ wide, $6 \mathrm{~m}$ long, and $0.5 \mathrm{~m}$ deep. As the bottom and sides of the tank were made of transparent acrylic material, the waves could be observed from any direction (Fig. 2). The 


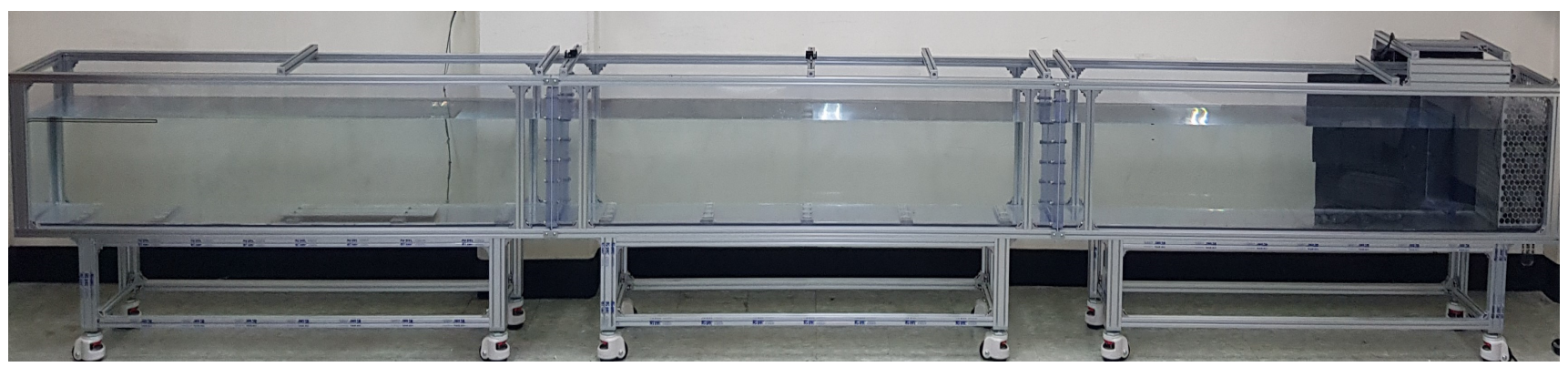

Fig. 2 Overview of Two-dimensional mini wave tank

piston-type wave maker was installed in this tank (not an activedamping wave maker). The experiment was conducted by excluding the effect of reflected waves by measuring the wave before the generated wave was re-reflected by the wave maker. A $0.1 \mathrm{~s}$ period interval was used in a $0.8-1.2 \mathrm{~s}$ range of the incident wave period, and the wavelength was $0.98-1.86 \mathrm{~m}$.

Uniform regular waves were generated at a wave height of $0.5 \mathrm{~cm}, 1$ $\mathrm{cm}, 2 \mathrm{~cm}$, and $3 \mathrm{~cm}$, respectively. Wave data were collected 20 times per second using wave gauges. Fig. 3 shows the side view and plan view of the overall schematics of the $2 \mathrm{D}$ mini wave tank with the punching plates installed. Table 1 shows the experimental conditions for wave length for each wave period.

Table 1 Wave conditions

\begin{tabular}{cc}
\hline Wave period & Wave length \\
\hline $0.8 \mathrm{~s}$ & $0.977 \mathrm{~m}$ \\
$0.9 \mathrm{~s}$ & $1.201 \mathrm{~m}$ \\
$1.0 \mathrm{~s}$ & $1.425 \mathrm{~m}$ \\
$1.1 \mathrm{~s}$ & $1.645 \mathrm{~m}$ \\
$1.2 \mathrm{~s}$ & $1.861 \mathrm{~m}$ \\
\hline
\end{tabular}

In the side view shown in Fig. 3, the water depth $(h)$ was $0.35 \mathrm{~m}$, and the flat punching plate (Position A) was installed such that it was submerged $0.01 \mathrm{~m}$ (Gap) from the free surface. The ultrasonic wave gauges were named as wave gauge \#1 $\left(W_{1}\right), \# 2\left(W_{2}\right), \# 3\left(W_{3}\right)$, and \#4 $\left(W_{4}\right)$, respectively. The spacing between each wave gauge was all set uniformly to $0.3 \mathrm{~m}$, and the spacing $\left(L_{k}\right)$ between the wave maker and wave gauge $\# 1\left(W_{1}\right)$ was set to be $2 \mathrm{~m}$ considering the evanescent wave mode. The length $(a)$ of the flat punching plate was $0.5 \mathrm{~m}$, and in Case 1, the length $(b)$ and angle $(\theta)$ of the sloping punching plate were $1 \mathrm{~m}$ and $18.6^{\circ}$, respectively. The experiment was conducted on three conditions for the length $(b)$ and angle $(\theta)$ of the sloping punching plate. In the plan view of Fig. 3, the width of the wave tank $(c)$ was 0.3 $\mathrm{m}$, and in Case 1 , the projected length $\left(b^{\prime}\right)$ of the sloping punching plate was $0.94 \mathrm{~m}$. The signals measured by the ultrasonic wave gauges were amplified using an amplifier (AMP) and sent to a data acquisition device (DAQ). Then, the data were stored and analyzed on a computer.

\subsection{Punching Plate Wave Absorber}

The wave absorber was installed at the end of the mini wave tank by combining a flat punching plate and a sloping punching plate. Fig. 4 shows a schematic diagram of the punching plates used in the wave

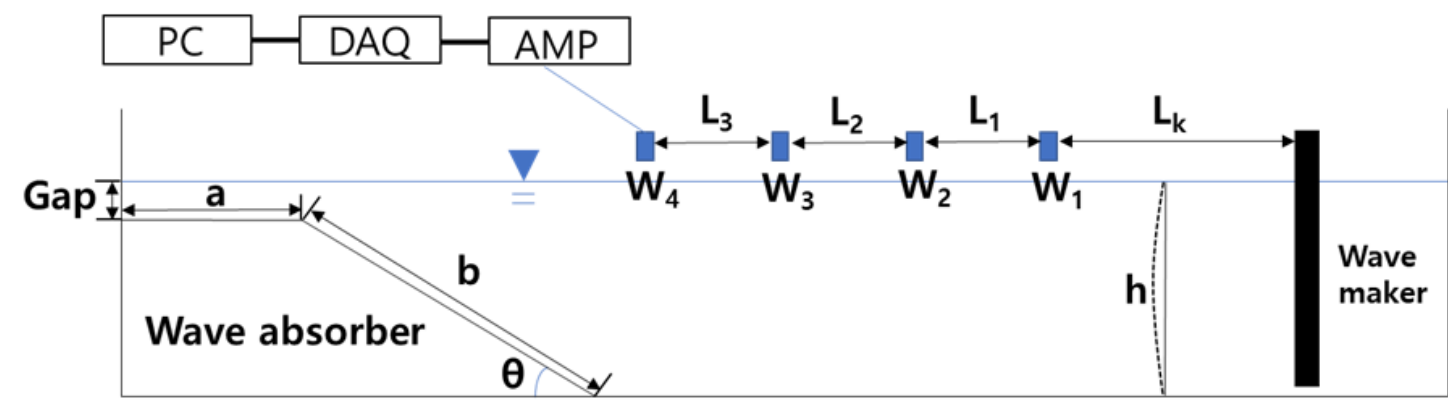

Side View

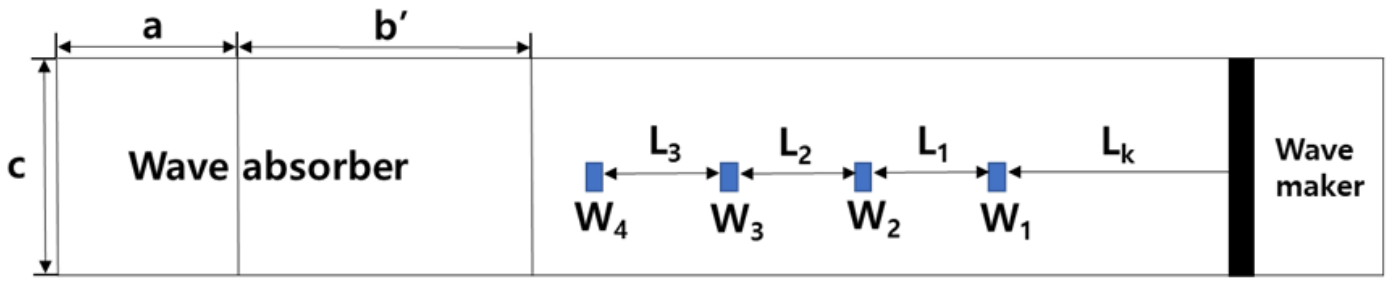

Plan View

Fig. 3 Overview of an experimental setup 


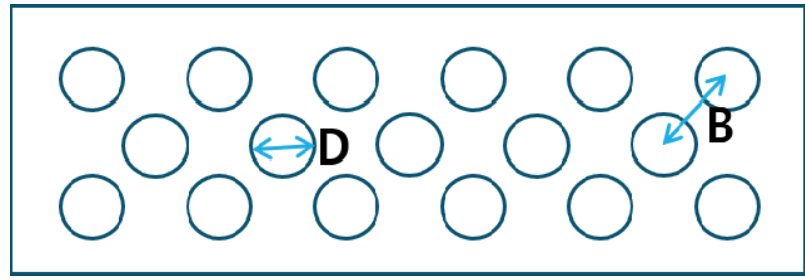

Fig. 4 Conceptual drawing of a punching plate wave absorber

absorber. Holes of the same diameter $(D)$ and spacing $(B)$ were drilled onto the plates to maximize the wave absorption effect. $D$ and $B$ of all punching plates were identical, and the number of pores (circles) varied depending on the porosity of the punching plate. The punching plates were fabricated using an acrylic material having a thickness of $10 \mathrm{~mm}$.

Fig. 5 shows the punching plate corresponding to the flat plate of the combined wave absorber. The dimension of the flat punching plate was $500 \times 298 \mathrm{~mm}$. In this study, porosity $(P)$ is given as a ratio of the perforated area to the total area of the plate.

Fig. 6 shows the sloping punching plate with various porosities having the dimension of $1000 \times 298 \mathrm{~mm}$, and Table 2 shows the dimension of the flat and sloping punching plates. Each punching plate was fabricated with a porosity of approximately $0 \%-20 \%$ (Table 3 ). In this study, we conducted the experiment by changing the installation angle and length (Table 2$)$ at a porosity of $0 \%(P=0)$ for the sloping punching plate (b).

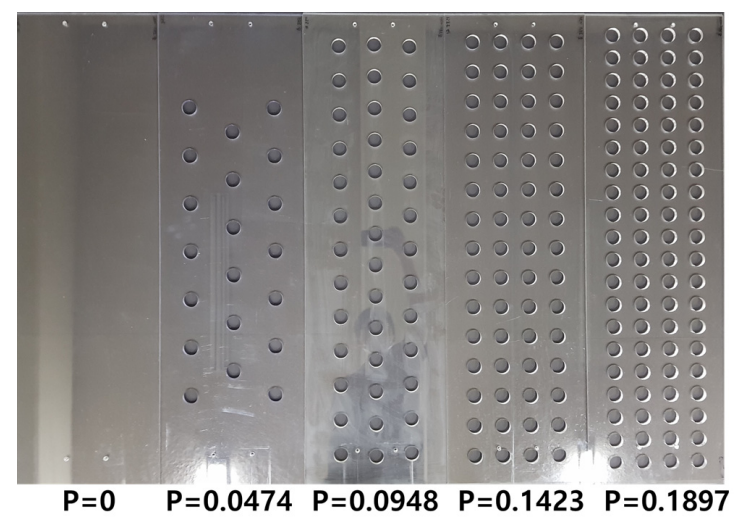

Fig. 6 Various porosities of sloping punching plate

Table 2 Dimension of wave tank with a sloped wave absorber

\begin{tabular}{crrr}
\hline \multirow{2}{*}{ Parameter } & \multicolumn{3}{c}{ Condition } \\
\cline { 2 - 4 } & Case 1 & Case 2 & Case 3 \\
\hline$a$ (Flat plate length) & $1 \mathrm{~m}$ & $0.5 \mathrm{~m}$ \\
$b$ (Sloping plate length) & $0.53 \mathrm{~m}$ & $0.33 \mathrm{~m}$ \\
$b^{\prime}$ (Sloping projection length) & $0.94 \mathrm{~m}$ & $0.41 \mathrm{~m}$ & $0 \mathrm{~m}$ \\
$L$ (Wave gauge interval) & $0.3 \mathrm{~m}$ \\
$L_{k}$ & $2 \mathrm{~m}$ \\
$h$ (Water depth) & $0.35 \mathrm{~m}$ \\
Gap & $0.01 \mathrm{~m}$ \\
$c$ (Tank width) & & $0.3 \mathrm{~m}$ & \\
$\theta$ (Theta) & $18.6^{\circ}$ & $39.3^{\circ}$ & $90^{\circ}$ \\
\hline
\end{tabular}

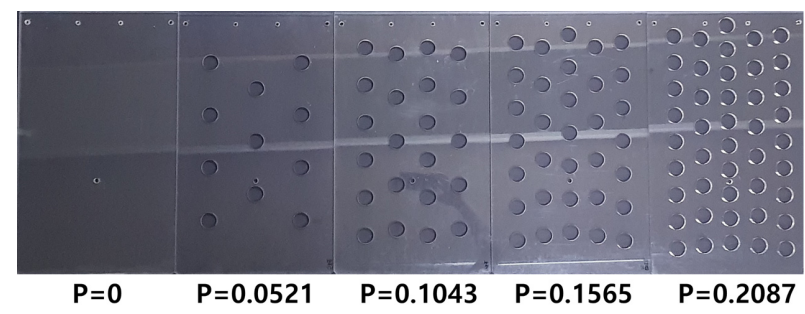

Fig. 5 Various porosities of flat punching plates

Table 3 Dimension of punching plates

\begin{tabular}{cccc}
\hline & $\begin{array}{c}\text { Porosity } \\
(\%)\end{array}$ & $\begin{array}{c}\text { Number of } \\
\text { circles }\end{array}$ & $\begin{array}{c}\text { Diameter of hole } \\
(D)(\mathrm{mm})\end{array}$ \\
\hline Flat & 0 & - & - \\
plate & 5.22 & 11 & 30 \\
& 10.44 & 22 & 30 \\
& 15.65 & 33 & 30 \\
& 20.87 & 44 & 30 \\
Sloping & 0 & - & - \\
plate & 4.74 & 20 & 30 \\
& 9.49 & 40 & 30 \\
& 14.23 & 60 & 30 \\
& 18.98 & 80 & 30 \\
\hline
\end{tabular}

\subsection{Ultrasonic Wave Height Gauge}

In this experiment, we used Senix TSPC-30S2 ultrasonic wave gauges, whose picture and specifications are shown in Fig. 7 and Table 4. Each ultrasonic wave gauge was installed in the vertical direction on the free surface. This device measures the height of the free surface by measuring the time that the ultrasonic wave generated by the wave gauge is reflected at the free surface. The wave gauges have a built-in temperature compensation circuit because the propagation speed of ultrasonic waves is slower in air than in water. Furthermore, the change in speed of ultrasonic waves due to temperature change cannot be ignored.

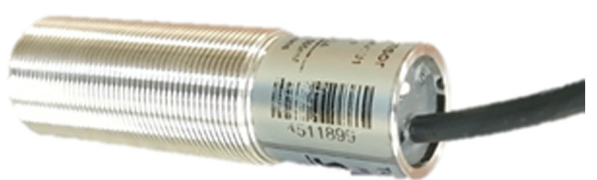

Fig. 7 Ultrasonic wave height gauge (TSPC-30S2)

Table 4 Specifications of TSPC-30S2

\begin{tabular}{cc}
\hline Measuring distance & $4.4-61 \mathrm{~cm}($ Max. 91 cm) \\
Resolution & $0.086 \mathrm{~mm}$ \\
Sampling rate & $20 \mathrm{~Hz}(50 \mathrm{~ms})$ \\
Interface & RS-485 \\
\hline
\end{tabular}

\section{Results and Analysis of Reflected Wave Separation Experiment}

Fig. 8 shows the time-series results comparing the change in the free 
surface when the wave absorber was installed and when it was not installed. Here, a combined punching plate with an average porosity of $10 \%(P=0.0980)$, which combined a flat punching plate with a porosity of $10 \%(P=0.1043)$ and a sloping punching plate with a porosity of $10 \%(P=0.0948)$, was installed as the wave absorber, and the time series data measured by the third wave gauge were compared. The wave period of the incident wave was $1.2 \mathrm{~s}$ and the wave height was $2 \mathrm{~cm}$. The free surface elevation measured between approximately 6 and $9 \mathrm{~s}$ after the generation of an incident wave confirmed that the steady-state was shown irrespective of whether the wave absorber was installed or not. Therefore, it was determined that the reflected waves did not enter the measurement section of the mini wave tank completely. However, after approximately $9 \mathrm{~s}$, when the incident wave was reflected from the end wall of the tank entered the measurement section after being re-reflected by the wave maker plate, the free surface elevation increased by approximately $100 \%$ in the case of no wave absorber. On the other hand, when the combined punching plate

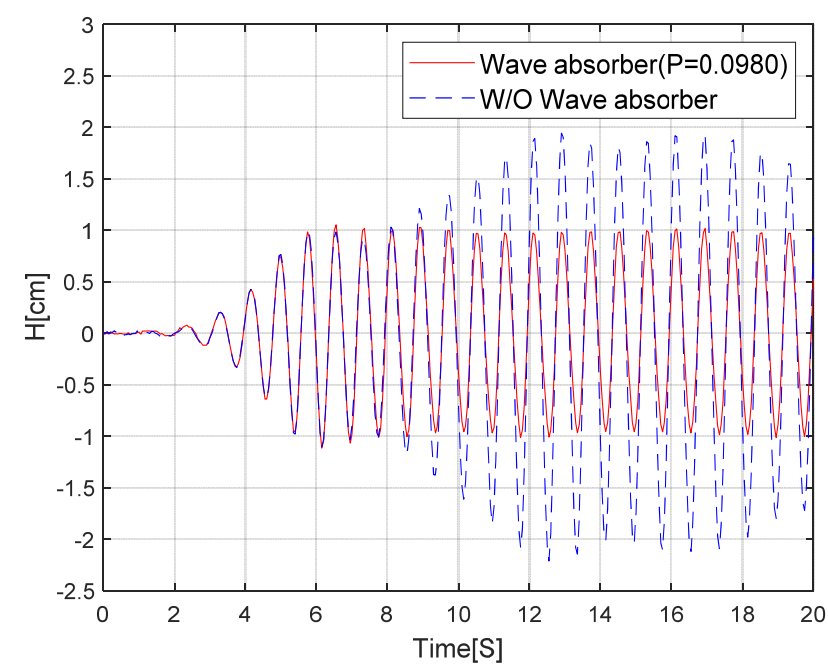

Fig. 8 Time series of measured wave elevations at the 3rd wave gauge $(T=0.8 \mathrm{~s}, H=2 \mathrm{~cm})$

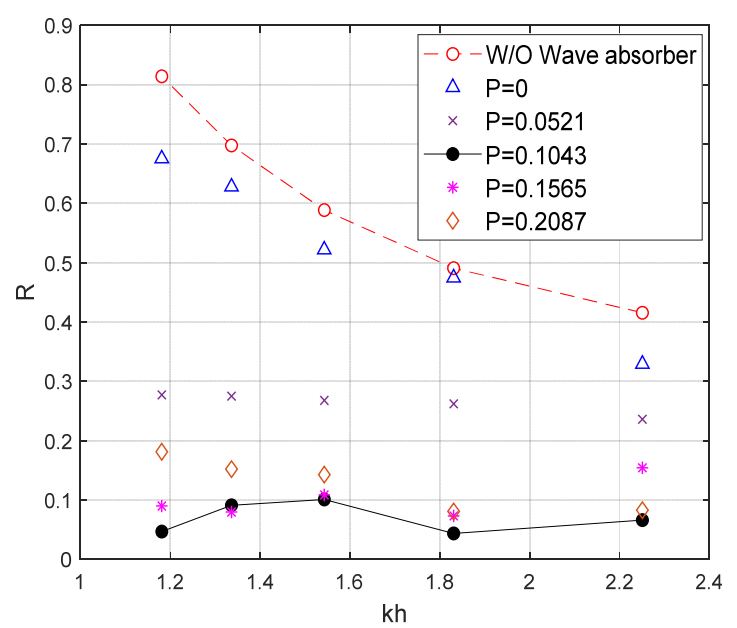

Fig. 9 Comparison of reflection coefficients on various porosity conditions with a flat punching plate wave absorber $(H=$ $2 \mathrm{~cm})$ was installed, crest and trough values of the free surface elevations were well maintained in a section of $2 \mathrm{~cm}$, i.e., the incident wave height. This meant that the incident wave was no longer reflected from the wave absorber and most of the energy was dissipated, thereby showing the wave absorption performance of the punching plate.

Based on these results, we compared the wave absorption performance of the flat punching plate (Fig. 9) and combined punching plate (Fig. 10) according to the porosity of the punching plate in terms of the reflection coefficient. Here, $R$ denotes the reflection coefficient, $k$ denotes the wave number, and $h$ denotes the water depth. The incident waves were generated at $0.1 \mathrm{~s}$ intervals with wave height of 2 $\mathrm{cm}$ and wave period of $0.8-1.2 \mathrm{~s}$. The experiment was performed using punching plates with five porosities $(P=0-0.2087)$.

Fig. 9 shows that the reflection coefficient is similar for when a flat punching plate with $0 \%$ porosity $(P=0)$ is installed and when no punching plate is installed. Furthermore, the reflection coefficient generally increases from the short-wave to the long-wave. This shows that although the flat punching plate $(0 \%$ porosity, $P=0)$ has been installed, the incident waves are not attenuated by the flat plate alone. However, when the flat plate was porous, considerably superior wave absorption performance was observed, and particularly, good wave absorption performance was confirmed for long-waves. Furthermore, it was confirmed that the deviation of the reflection coefficient according to the wavelength was not very large. When the porosity of the flat punching plate was approximately $5 \%(P=0.0521)$, the reflection coefficient was less than or equal to 0.3 , but when the porosity was approximately $10 \%(P=0.1043)$, the reflection coefficient was less than or equal to 0.1 , i.e., it demonstrated the best wave absorption performance. However, for a large porosity of $20 \%$ ( $P=0.2087)$, the reflection coefficient increased rather slightly in the long-wave region $(k h=1.2)$. In brief, when the porosity was $10 \%$ ( $P=$ 0.1043 ) on the flat punching plate, the mean reflection coefficient was approximately 0.07 , i.e., the best reflection coefficient.

Fig. 10 compares the reflection coefficient of different incident

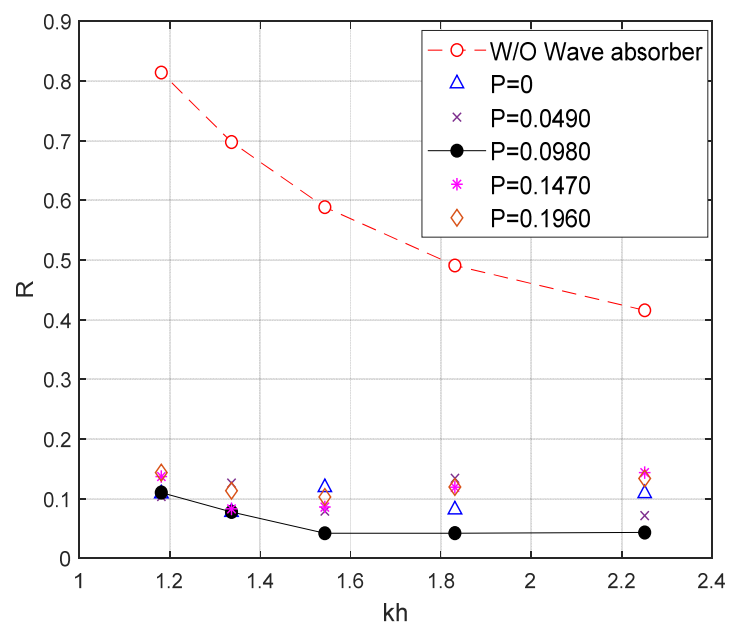

Fig. 10 Comparison of reflection coefficients on various porosity conditions with a combined punching plate wave absorber $(H=2 \mathrm{~cm})$ 


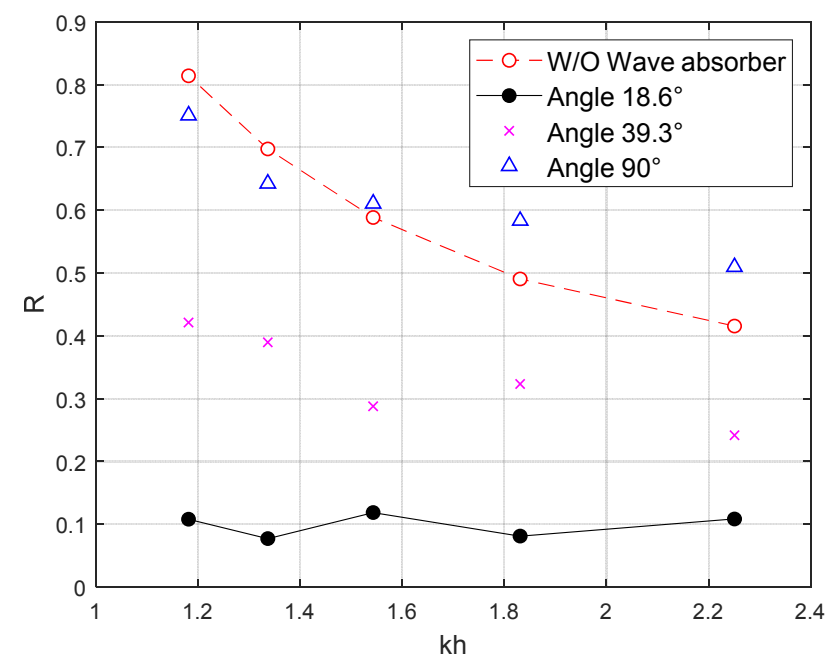

Fig. 11 Comparison of reflection coefficients on various plate angles with a combined punching plate wave absorber $(P=0, H=2 \mathrm{~cm})$

wavelengths for the combined punching plate. The porosity was identical between the flat plate and sloping plate in each condition. The combined punching plate was inclined at $18.6^{\circ}$. Compared with the flat punching plate case (Fig. 9), a significantly better wave absorption performance was observed with a reflection coefficient of approximately 0.1 for $0 \%$ porosity condition $(P=0)$. Based on this, it was determined that the installation of the sloping plate results in a shoaling effect of incident waves, and the wave energy decreases due to the interaction with the flat plate. Similar to the case of the flat punching plate, it was confirmed that the best wave absorption performance (a low reflection coefficient) was observed for a porosity of $10 \%(P=0.0980)$ under the combined punching plate condition. This shows that the optimal porosity was generally approximately $10 \%$ irrespective of the incident wavelength. Cho (2013) also obtained similar results. Therefore, it can be expected that the energy loss rate of the incident wave is the largest when the porosity of the punching plate is $10 \%$. As reported by Ko and Cho (2018), the load on the punching plates is expected to decrease if the porosity increases. This is because the pressure difference between the punching plates decreases. Furthermore, for the combined punching plate, the effect of installing the sloping punching plate is greater than the wave absorption performance produced by the porosity change.

Fig. 11 shows the comparison of wave absorption performance between various slope angles of the sloping plate of a combined wave absorber with $0 \%$ porosity $(P=0)$. When the installation angle of the sloping plate was $90^{\circ}$, the result was very similar to that of the case where there was no wave absorber. Moreover, the reflection coefficient increased in the short-wave region. When the angle of the sloping plate was $39.3^{\circ}$, the reflection coefficient was approximately 0.3 to 0.4 , showing a certain degree of wave absorption performance. However, when the slope angle was $18.6^{\circ}$, the best wave absorption performance was recorded. Therefore, for the given conditions of this experiment (incident wave period: $0.8-1.2 \mathrm{~s}$, water depth: $0.35 \mathrm{~m}$ ), it

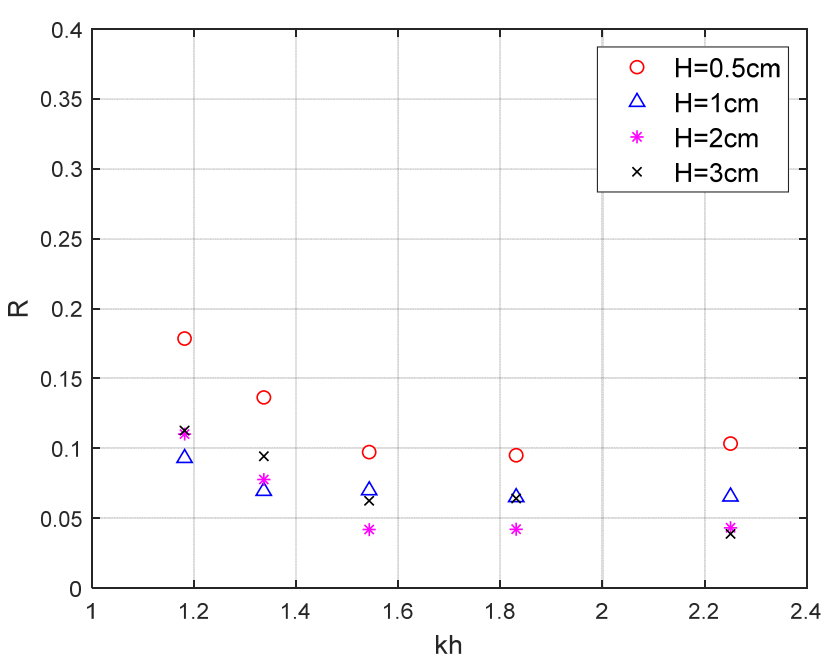

Fig. 12 Comparison of reflection coefficients on various wave heights with a combined punching plate wave absorber $(P=0.098$, case 1$)$

was appropriate to maintain the angle of the sloping plate at approximately $18.6^{\circ}$ to achieve effective wave absorption performance. Ko and Cho (2018) reported that the optimal angle for the sloping punching plate ranged from $10^{\circ}-20^{\circ}$. Therefore, we determined the angle that can produce an appropriate shoaling effect when an incident wave enters the punching plate area. In this experiment, no breaking wave occurred on the sloping punching plate. However, some breaking waves occurred on the flat punching plate because the waves that entered the flat plate were reflected at the end wall of the wave tank, resulting in superposed waves.

Fig. 12 shows the comparison of the change in wave absorption performance of the combined punching plate at different incident wave heights. The sloping plate was inclined at $18.6^{\circ}$ and the porosity of the combined punching plate was $10 \%(P=0.098)$. When the incident wave height was $0.5 \mathrm{~cm}$, the reflection coefficient increased in all wave frequencies. This is because the installation depth of the flat punching plate was $1 \mathrm{~cm}$ below the free surface, so when the incident wave height is small, the wave absorption effect of the flat punching plate cannot be expected. When the wave height was greater than $1 \mathrm{~cm}$, the reflection coefficient was less than or equal to 0.1 , which showed significantly effective wave absorption performance. Generally, similar wave absorption performance was shown irrespective of the wave height. Furthermore, the reflection coefficient generally increases as the incident wavelength increases (as $k h$ decreases). This result is similar to the conclusion of a study conducted by Yuan et al. (2013), which states that the reflection rate increases as the wave frequency increases on a sloping punching plate.

Overall, combined punching plates have better wave absorption performance than separated punching plates. As the flat plate is combined with the sloping plate, the incident water particles with a circular or elliptical trajectory produce a shoaling effect with the sloping plate, thereby increasing the wave height. Here, as the water particles near the free surface enter more above the flat plate, the wave 
energy is attenuated at the pores of the flat plate, and additional energy is attenuated as the waves reflected from the end wall of the wave tank are superposed, thereby breaking the waves. The energy of wave particles below the free surface is consumed at the pores of the sloping plate. Therefore, it is understood that a significant amount of wave energy is attenuated on the flat punching plate, and additional wave energy is consumed by the sloping punching plate.

\section{Conclusion}

In this study, we proposed a combined wave absorber by combining a flat punching plate and a sloping punching plate. Additionally, the wave absorption performance of the proposed wave absorber was comparatively analyzed according to the porosity of the punching plates, existence/absence of the sloping punching plate, installation angle of the sloping plate, and incident wave height. The punching plate wave absorber was installed in a $2 \mathrm{D}$ mini wave tank having a length of $6 \mathrm{~m}$ to conduct the experiments. We installed four wave gauges and separated the reflected waves by using a least square method to analyze the reflection coefficient to determine the wave absorption performance.

For installing the punching plate wave absorber, it was confirmed via time series comparisons that the reflected waves were suppressed and incident waves of the steady-state were measured for a long time. When the flat punching plate was installed, the wave absorption performance was excellent at a porosity of $10 \%(P=0.1043)$.

When the combined punching plate was installed with a porosity of $10 \%(P=0.0980)$ with the punching plate having an installation angle of $18.6^{\circ}$, the reflection coefficient was reduced by up to $95 \%$, thereby showing the most effective wave absorption performance. This means that the combination of a flat punching plate and a sloping punching plate can effectively attenuate the incident wave energy. When the incident wave height was greater than the installation depth of the flat punching plate, the difference in wave absorption performance due to the wave height change was not that large, and all cases showed excellent performance.

The installation angle of the sloping plate produces a shoaling effect when the incident wave enters the plate, thereby increasing the incident wave height. The wave absorption performance can be improved if more water particles enter above the flat punching plate. However, owing to the limitations of the experimental equipment and physical conditions, additional comparisons and a precise analysis of wave absorption performance are required for more segmented slope angles in the future.

\section{Conflict of interest}

No potential conflict of interest relevant to this article was reported.

\section{Funding}

This research was conducted with the support of the Korea Institute for Advancement of Technology (KIAT) as a source of the "Industry Professional Manpower Competency Reinforcement Project" of the Ministry of Trade, Industry, and Energy. (2020 Future Ocean Plant Global Advanced Professional Training Project, No.: P0012646). In addition, This research is supported by the National Research Foundation of Korea, a basic research project in the field of science and engineering (NRF-2018R1D1A1B07040677).

\section{References}

Cho, I.H. (2013). Reflection and Transmission Coefficients by a Surface-Mounted Horizontal Porous Plate. Journal of Korean Society of Coastal and Ocean Engineers, 25(5), 327-334. https://doi.org/10.9765/KSCOE.2013.25.5.327

Cho, I.H., \& Hong, S.W. (2004). Development of a Wave Absorbing System Using an Inclined Punching Plate. Journal of Ocean Engineering and Technology, 18(1), 1-6.

Goda, Y., \& Suzuki, Y. (1977). Estimation of Incident and Reflected Waves in Random Wave Experiments. Proceedings of $15^{\text {th }}$ International Coastal Engineering, Honolulu, Hawaii, United States, 828-845. https://doi.org/10.1061/9780872620834.048

Jung, H.J., \& Cho, I.H. (1999). Experimental Study of WaveAbsorbing Performance by Horizontal Punching Plates. Journal of the Korean Society for Marine Environment \& Energy, 2(1), 40-48.

Ko, C.H., \& Cho, I.H. (2018). Reflection of Porous Wave Absorber Using Quasi-Linear Numerical Model. Journal of Korean Society of Coastal and Ocean Engineers, 30(1), 1-9. https://doi. org/10.9765/KSCOE.2018.30.1.1

Mansard, E.P., \& Funke, E.R. (1980). The Measurement of Incident and Reflected Spectra Using a Least Squares Method. Proceedings of $17^{\text {th }}$ International Coastal Engineering, Sydney, Australia, 154-172. https://doi.org/10.1061/9780872622647.008

Park, W.S., Oh, Y.M., \& Chun, I.S. (1992). Separation Technique of Incident and Reflected Waves Using Least Squares Method. Journal of Korean Society of Coastal and Ocean Engineers, 4, 139-145.

Suh, K., Park, W.S., \& Park, B.S. (2001). Separation of Incident and Reflected Waves in Wave-Current Flumes. Coastal Engineering, 43(3-4), 149-159. https://doi.org/10.1016/S0378-3839(01)00011-4 Yuan, Z.Z., Jung, E.C., \& Hee-Chang, L.I.M. (2013). Study of a Sloping-Wall-Type Wave Absorber Placed in Various Sinusoidal Propagate Waves. Proceedings of Spring Conference of The Korean Society of Mechanical Engineers, 147-152.

\section{Author ORCIDs}

\section{Author name}

Jung, Hyen-Cheol

Koo, Weoncheol
ORCID

0000-0003-1274-8844

0000-0002-4384-0996 


\section{Appendix}

The variables of Eq. (4) in the paper are represented by Eqs. (A1)(A4).

$$
\begin{aligned}
& X_{1}=\frac{H_{I}}{2} \cos \left(\varepsilon_{I}\right) \\
& X_{2}=\frac{H_{R}}{2} \cos \left(\varepsilon_{R}\right) \\
& X_{3}=\frac{H_{I}}{2} \sin \left(\varepsilon_{I}\right) \\
& X_{4}=\frac{H_{R}}{2} \sin \left(\varepsilon_{R}\right)
\end{aligned}
$$

The coefficients in Eq. (6) are represented by Eqs. (A5) and (A6).

$$
\begin{aligned}
& C_{11}=\sum_{k=1}^{N} \int_{0}^{T_{m}} \cos ^{2}\left(w t-k l_{n}\right) d t \\
& C_{12}=C_{21}=\sum_{k=1}^{N} \int_{0}^{T_{m}} \cos \left(w t-k l_{n}\right) \sin \left(w t+k l_{n}\right) d t \\
& C_{13}=C_{31}=\sum_{k=1}^{N} \int_{0}^{T_{m}} \cos \left(w t-k l_{n}\right) \sin \left(w t-k l_{n}\right) d t \\
& C_{14}=C_{41}=\sum_{k=1}^{N} \int_{0}^{T_{m}}-\cos \left(w t-k l_{n}\right) \sin \left(w t+k l_{n}\right) d t
\end{aligned}
$$

$$
C_{22}=\sum_{k=1}^{N} \int_{0}^{T_{m}} \cos ^{2}\left(w t+k l_{n}\right) d t
$$$$
C_{23}=C_{32}=\sum_{k=1}^{N} \int_{0}^{T_{m}} \cos \left(w t+k l_{n}\right) \sin \left(w t-k l_{n}\right) d t
$$$$
C_{24}=C_{42}=\sum_{k=1}^{N} \int_{0}^{T_{m}}-\cos \left(w t+k l_{n}\right) \sin \left(w t+k l_{n}\right) d t
$$$$
C_{33}=\sum_{k=1}^{N} \int_{0}^{T_{m}} \sin ^{2}\left(w t-k l_{n}\right) d t
$$$$
C_{34}=C_{43}=\sum_{k=1}^{N} \int_{0}^{T_{m}}-\sin \left(w t-k l_{n}\right) \sin \left(w t+k l_{n}\right) d t
$$$$
C_{44}=\sum_{k=1}^{N} \int_{0}^{T_{m}} \sin ^{2}\left(w t+k l_{n}\right) d t
$$

$$
\begin{aligned}
& F_{1}=\sum_{k=1}^{N} \int_{0}^{T_{m}} \cos \left(w t-k l_{n}\right) \zeta_{n}(t) d t \\
& F_{2}=\sum_{k=1}^{N} \int_{0}^{T_{m}} \cos \left(w t+k l_{n}\right) \zeta_{n}(t) d t \\
& F_{3}=\sum_{k=1}^{N} \int_{0}^{T_{m}} \sin \left(w t-k l_{n}\right) \zeta_{n}(t) d t \\
& F_{4}=\sum_{k=1}^{N} \int_{0}^{T_{m}}-\sin \left(w t+k l_{n}\right) \zeta_{n}(t) d t
\end{aligned}
$$

